\title{
Correlation of urinary thioethers with chemical exposure in a rubber plant
}

\author{
I KILPIKARI \\ From the Department of Occupational Health, Oy Nokia Ab, SF-37101 Nokia, Finland
}

\begin{abstract}
Exposure to potentially alkylating agents in a rubber factory was measured by determining thioether concentrations in urine samples collected at the end of work on a Friday. The study population consisted of the total work force (113) in the production departments of a factory, and office clerks (111) in two factories of the same company. The highest excretion of thioethers was detected in female workers in the belt department who were exposed through the palmar skin. High excretion was also found in workers exposed to air-borne contaminants in the calender department and in workers in the raw material stores and chemical mixing sections. Lower values were found in the dispatching station and in the contaminant-free offices. Urinary thioether determination appears to be a reliable and easy method of assessing the exposure to certain rubber chemicals.
\end{abstract}

Many different chemical compounds are used in the rubber and other elastomer industries. The number of individual chemical compounds exceeds $500,{ }^{1}$ and they may be divided into vulcanisers, catalysts, antioxidants, activators, and filling compounds. Many of these chemicals are water- and lipid-soluble and may be absorbed readily through the skin. Several phases in the production of rubber require manual handling of the material by workers so that chemicals may be absorbed by inhalation and through the skin. This may invalidate the control of exposure by the determination of the air-borne concentration of contaminants, but no practical method is available for controlling percutaneous absorption of chemical compounds. Furthermore, some chemicals may impair or facilitate the absorption of others; thus the simple measurement of the amount of material on the skin at the end of the work shift is not informative.

Our own earlier experience indicates that the absorbed fraction may be estimated by analysing the urinary excretion of their metabolites. ${ }^{2}$ The major advantage of determining the thioether fraction in urine is that it reflects the absorption of chemicals capable of forming reactive compounds irrespective of the mode of entry and perhaps of their propensity to play a role in carcinogenesis. ${ }^{3}$ The purpose of the present study was to evaluate further the validity of urinary thioether analysis by examining the excretion of thioethers by every employee in a rubber plant.

Received 10 January 1980

Accepted 14 April 1980

\section{Subjects and methods}

\section{SUBJECTS}

The exposed population consisted of 113 workers, 23 women and 90 men; office clerks of two rubber plants (48 women and $63 \mathrm{men}$ ) served as controls. Freshly voided urine samples were collected at the end of an eight-hour working day on a Friday and stored at $-25^{\circ} \mathrm{C}$ until analysis. Medication and smoking habits were assessed through predistributed questionnaires.

\section{EXPOSURE}

The process in this belt factory comprises a raw material store and mixing department followed by calenders and production sections where the manufacture, curing, and finishing take place. The finished products are often stored for varying periods before they are transported for retail.

The major hygiene problem at the initial stages of the process is due to a mixture of organic dusts generated by the handling of materials in the mill area. At the next stage, breakdown products form another source of contamination at the calenders. The process then divides into two belt production lines with somewhat different exposures. The percutaneous route of absorption of chemicals is of major interest in both types of manufacture because the concentration of air-borne contaminants is low. The curing process forms the typical elastic texture of the finished articles with no further liberation of 
Table 1 Mean urinary thioether excretion by sex and department. Values are expressed as $\mu m o l / m m o l$ creatinine $\pm S E$. (Number of subjects in parentheses)

\begin{tabular}{|c|c|c|c|}
\hline Department & Men & Women & \\
\hline Raw material and processing & $53 \pm 5(8)$ & - & \\
\hline Calendering & $58 \pm 6(10)^{*}$ & - & \\
\hline Calender 2 & $43 \pm 4(5)$ & - & \\
\hline Conveyor belt & $43 \pm 4(19)$ & $71 \pm 13(2)$ & \\
\hline Wedge belt & $44 \pm 4(16)$ & $89 \pm 12(15) \ddagger$ & \\
\hline Wedge belt making & - & $95 \pm 10(5) \ddagger$ & \\
\hline Storage and transportation & $33 \pm 5(6)$ & - & \\
\hline Service & $50 \pm 4(27) \ddagger$ & $61 \pm 7(5)$ & \\
\hline Controls & $37 \pm 2(63)$ & $42 \pm 2(48)$ & - \\
\hline
\end{tabular}

$* \mathrm{p}<0.01$ as compared with controls.

tp $<0.025$ as compared with calender two.

$\ddagger \mathrm{p}<0.005$ as compared with controls.

added chemicals. Therefore, exposure after curing is probably negligible.

The two calenders are used for different types of rubber. The first is used mainly for rubber containing hexamethylenetetramine-resorcinol resin, while different types of mixtures are directed to the second calender. Uncured rubber coming from each calender is manufactured equally by the belt production lines. Although the exposure to hexamethylenetetramine rubber is in principle equal in both lines, there is substantially less skin contamination by rubber in the conveyor belt line.

The skin contamination by rubber of every worker was estimated by one foreman and two physicians on the basis of a half-day observation and knowledge of the jobs. The workers were divided into three categories: heavy, moderate, and light exposure depending on whether the contamination time was $60-100 \%, 40-60 \%$, or less than $40 \%$ of the total work time.

\section{ANALYSIS OF URINARY THIOETHERS AND} STATISTICAL METHODS

Urinary thioethers were determined after alkaline hydrolysis as described by Vainio et $a l^{2}$ and expressed as $\mu \mathrm{mol}$ of urinary thioether per mmol of creatinine in order to adjust for differences in the concentration of urine. The results were evaluated by Student's $t$ test as modified by Cochran. ${ }^{4}$

\section{Results}

The mean urinary thioether excretion, expressed as $\mu \mathrm{mol} / \mathrm{mmol}$ creatinine $\pm \mathrm{SE}$, was $47 \pm 1.8$ for 90 cases and $37 \pm 1.6$ for 63 controls among men, and $77 \pm 8 \cdot 5$ for 23 cases and $42 \pm 2 \cdot 3$ for 48 controls among women. Cigarette smoking and medication may confound the potential association between occupational exposure and output of thioether. Among men, smoking and medication were equally prevalent among cases and controls, whereas $34 \%$ of female cases and $17 \%$ of female controls were exposed to cigarettes or medication, or both. In this group the smoking and medication-adjusted mean of urinary thioether excretion was $0.9 \mu \mathrm{mol} / \mathrm{mmol}$ creatinine higher than the control concentration of $42 \mu \mathrm{mol} / \mathrm{mmol}$ creatinine. Because of the small effect of smoking and medication, unadjusted figures were used in the results.

The highest mean excretion of thioethers was found among female wedge belt workers (table 1). The mean for all wedge belt workers was $66 \pm 8$ $\mu \mathrm{mol} / \mathrm{mmol}$ creatinine (31 workers) and that for all conveyor belt workers was $45 \pm 4 \mu \mathrm{mol} / \mathrm{mmol}$ creatinine (21 workers) $(\mathrm{p}<0.025)$. High excretion of urinary thioether was also found among workers in the calender department (table 1). Workers operating calender No 1 had a mean of $69 \mu \mathrm{mol} /$ mmol creatinine, which was significantly higher than that of workers on calender No $2(43 \mu \mathrm{mol} / \mathrm{mmol}$ creatinine, $p<0.025)$. Service workers had significantly higher excretion $(p<0.005)$ than the controls. There was a significant difference (table 2 ) in the thioether excretion of male workers handling uncured rubber as compared with either workers handling cured rubber or with controls. The difference among female workers was significant only

Table 2 Mean urinary thioether excretion by sex and by curing status of rubber. Values are expressed as $\mu \mathrm{mol} / \mathrm{mmol}$ creatinine $\pm S E$. (Number of subjects in parentheses)

\begin{tabular}{lll}
\hline Rubber & Men & Women \\
\hline Cured & $37 \pm 3(16)$ & $90 \pm 18(3)$ \\
Uncured & $49 \pm 2(26)^{*}$ & $86 \pm 13(14) \dagger$ \\
Controls & $37 \pm 2(63)$ & $42 \pm 2(48)$ \\
\hline
\end{tabular}

$* \mathrm{p}<0.01$ as compared with controls or with workers handling cured rubber.

tp $<0.005$ as compared with controls. 
Table 3 Mean urinary thioether excretion by handling time of uncured rubber (women). Values are expressed as $\mu \mathrm{mol} / \mathrm{mmol}$ creatinine $\pm S E$. (Number of subjects in parentheses)

\begin{tabular}{lr}
\hline Category by skin contamination & Thioether excretion \\
\hline Heavy $(60-100 \%)$ & $115 \pm 20(6)^{*}$ \\
Moderate $(40-60 \%)$ & $74 \pm 14(8)$ \\
Light $(40 \%)$ & $57 \pm 3(3)$ \\
Controls & $42 \pm 2(48)$ \\
\hline
\end{tabular}

$* \mathrm{p}<0.02$ as compared with controls.

between the workers handling uncured rubber and controls. The contamination time of each woman who handled uncured rubber by hand was estimated and found to be related to urinary thioether excretion (table 3 ).

\section{Discussion}

Urinary thioethers are excretion products resulting from a series of metabolic reactions which involve oxidation of lipophilic chemicals to water-soluble compounds. The initial oxidation of foreign lipophilic molecules often produces chemically reactive epoxides or carbonium ions, which could be harmful unless removed from the reaction sphere by hydration or by conjugation. One such reactant is glutathione, with which a thioether bond is formed in the conjugation. The conjugated compounds are commonly excreted into the intestine in bile where the initial glutathione moiety is split into $\mathrm{S}$-alkyl-N-acetylthioserine. 5 The latter compound enters the circulatory system via an enterohepatic cycle, and part of the reabsorbed material is excreted through the kidneys. The initial conjugating enzyme, glutathioneS-transferase, accepts a very wide spectrum of substrates extending from ethylacrylate to methyl vinyl sulphone. 5

There is a difference in urinary baseline thioether excretion between men and women because of female steroids, especially oestrogen conjugates. ${ }^{5}$ In the present study the difference was $5 \mu \mathrm{mol} / \mathrm{mmol}$ creatinine among controls, whereas among cases the difference was higher, suggesting a difference in the exposure between men and women in some depart- ments. The longer contamination time for uncured rubber among wedge belt workers was associated with higher urinary thioether excretion as compared with conveyor belt workers. Wedge belt makers, mainly women, handle rubber throughout the working day, whereas conveyor belt makers handle uncured rubber for only short periods. Hence, handling of uncured rubber seems to lead to an appreciable percutaneous exposure.

Inhalation of chemicals and breakdown product fumes from heat-processed rubber at calendering also resulted in increased urinary thioether excretion. There was also a clear difference between the two calenders, although the machines are "quite similar. They use different rubber mixtures, however. Calender No 1 mainly uses rubber containing hexamethylenetetramine and resorcinol, which seemed to increase urinary thioether excretion more than other rubber compounds. These chemicals are used only when a good binding of rubber is needed-for instance, to textiles.

It further seems that fully vulcanised rubber articles do not give out contaminating chemicals, which will manifest themselves in high urinary thioether values.

Excretion of urinary thioethers correlated with the production scheme. Compared with methods estimating air-borne exposure, urinary thioether determination appears to be a reliable and easy method of assessing the exposure to rubber chemicals.

\section{References}

${ }^{1}$ Holmberg B, Sjöström B. Toxikologisk översikt över gummikemikalier. Arbetarskyddstyrelsen, Stockholm. Undersökningsrapport, 19:1-100.

${ }^{2}$ Vainio H, Savolainen H, Kilpikari I. Urinary thioether of employees of a chemical plant. Br J Ind Med 1978;35: 232-4.

${ }^{3}$ Garner RC. The role of epoxides in bioactivation and carcinogenesis. In: Bridges JW, Chasseaud LF, eds. Progress in drug metabolism. Vol 1. London: John Wiley and Sons, 1976:77-128.

${ }^{4}$ Snedecor GW, Cochran WG. Statistical methods. Ames, Iowa: Iowa State University Press, 1967:114-6.

${ }^{5}$ Chasseaud LF. Conjugation with glutathione and mercapturic acid excretion. In: Arias AM, Jakoby WB, eds. Glutathione: metabolism and function. New York: Raven Press, 1976:77-114. 